\title{
Incidences of overall and site specific cancers in TNF $\alpha$ inhibitor treated patients with rheumatoid arthritis and other arthritides - a follow-up study from the DANBIO Registry
}

\author{
Lene Dreyer, ${ }^{1}$ Lene Mellemkjær, ${ }^{2}$ Anne Rødgaard Andersen, ${ }^{3}$ Philip Bennett, ${ }^{4}$ \\ Uta Engling Poulsen, ${ }^{5}$ Torkell Juulsgaard Ellingsen, ${ }^{6}$ Torben Høiland Hansen, ${ }^{7}$ \\ Dorte Vendelbo Jensen, ${ }^{8}$ Louise Linde, ${ }^{3}$ Hanne Merete Lindegaard, ${ }^{9}$ Anne Gitte \\ Rasmussen Loft, ${ }^{10}$ Henrik Nordin, ${ }^{11}$ Emina Omerovic, ${ }^{12}$ Claus Rasmussen, ${ }^{13}$ \\ Annette Schlemmer, ${ }^{14}$ Ulrik Tarp, ${ }^{15}$ Merete Lund Hetland ${ }^{3} 16$
}

\begin{abstract}
- Additional supplementary files are published online only. To view these files please visit the journal online (http://dx.doi. org/10.1136/annrheumdis2012-201969)
\end{abstract}

For numbered affiliations see end of article.

\section{Correspondence to} Dr Lene Dreyer, Department of Rheumatology, Gentofte University Hospital, Niels Andersens Vej 65, 2900 Hellerup, Denmark; lene.dreyer@dadlnet.dk

Received 7 May 2012 Accepted 2 August 2012

\section{ABSTRACT}

Objectives To investigate the incidence of cancer in arthritis patients treated with or without TNF $\alpha$ inhibitors (TNF-I).

Methods Arthritis patients from the DANBIO database were followed-up for cancer in the Danish Cancer Registry during 2000-2008.

Results Hazard ratio for cancer overall was 1.02 (95\% confidence interval (Cl) 0.80-1.30) in 3347 TNF-I-treated RA patients compared to non-treated. Excess among TNF-I-treated was found for colon cancer (HR 3.52 195\% Cl 1.11-11.15), whereas 6 and 0 ovarian cancer cases were observed in treated and non-treated patients, respectively. Compared to the general population, TNF-Itreated RA patients had increased risk for cancer overall, cancer in lymphatic-haematopoietic tissue and nonmelanoma skin cancer, while non-RA patients had no increase in overall cancer risk.

Conclusions Our results suggest that TNF-I therapy in routine care is not associated with an overall excess of cancer in arthritis patients, but observed increased risks of colon and ovarian cancer need further investigation.

\section{INTRODUCTION}

Treatment with TNF $\alpha$ inhibitors (TNF-I) is widely used in inflammatory rheumatic diseases such as rheumatoid arthritis (RA), ankylosing spondylitis (AS) and psoriatic arthritis (PSA).

After more than 10 years of widespread use, it is still debated whether treatment with TNF-I agents is associated with an increase in cancer incidence, ${ }^{1-12}$ and additional observational studies with long-term follow-up, detailed drug history and independent registration of specific cancer cases are needed. The aim of the present study was to investigate the risk of cancer among TNF-I-treated patients by linking the national Danish DANBIO database of arthritis patients with the Danish Cancer Registry.

\section{MATERIALS AND METHODS DANBIO}

Since 2000 Danish rheumatologists have voluntarily registered patients treated with TNF-I agents in the DANBIO database, ${ }^{13}$ and in 2006 reporting became compulsory. Coverage for TNF-I-treated patients is steadily greater than $90 \%$. Since 2000 , an increasing number of both prevalent and newly diagnosed non-TNF-I-treated arthritis patients from rheumatology departments have also been registered in DANBIO. At the beginning reporting occurred on a voluntary basis but since 2006 the departments have been committed to register all newly diagnosed or newly referred RA patients. In 2006-7 a DANBIO-initiated cross-sectional study involving 11 of 26 Danish outpatient departments of rheumatology contributed with the registration of 3704 RA patients in DANBIO, among these 2977 were TNF-I naive. ${ }^{14}$

For details of the Central Population Register, the Danish Cancer Registry and statistical analysis, see supplementary material (available online only).

\section{Cohort identification and follow-up}

A total of 10495 patients registered in DANBIO between January 2000 and December 2008 was included. Among these patients, seven patients with systemic lupus erythematosus and 52 patients with a missing diagnosis were excluded. The remaining 10436 patients were linked to the Central Population Register (information on dates of death or emigration) and to the Danish Cancer Registry (identification of all cancer cases to 2008), and 740 patients with a cancer diagnosis before first registration in DANBIO were subsequently excluded, leaving 9696 patients with arthritis for analysis. Among these, 5345 started TNF-I therapy between January 2000 and the end of 2008, while 4351 patients had never been treated with anti-TNF $\alpha$ (table 1).

The cohort was followed from first registration in DANBIO until the date of first cancer diagnosis, death, emigration or the end of 2008, whichever came first. For patients who did not start treatment with TNF-I at the date of the first registration in DANBIO, the exposure status changed from never exposed to ever exposed at the date of the start of first TNF-I treatment $(n=1475)$. 
Table 1 Number of arthritis patients in DANBIO and characteristics of RA patients at first registration according to ever and never treatment with TNF-I

\begin{tabular}{|c|c|c|}
\hline & $\begin{array}{l}\text { Ever treated with } \\
\text { TNF-I* }\end{array}$ & $\begin{array}{l}\text { Never-treated with } \\
\text { TNF-I }\end{array}$ \\
\hline \multicolumn{3}{|l|}{ No of arthritis patients } \\
\hline All combined & 5345 & 4351 \\
\hline RA & 3347 & 3812 \\
\hline Ankylosing spondylitis & 861 & 136 \\
\hline Psoriatic arthritis & 656 & 224 \\
\hline Other arthritides & 481 & 179 \\
\hline \multicolumn{3}{|c|}{ Characteristics of RA patients at start of follow-up } \\
\hline $\begin{array}{l}\text { Mean age at start of follow-up, } \\
\text { years (range) }\end{array}$ & $54.3(15-87)$ & $61.2(15-92)$ \\
\hline Mean age at diagnosis, years & 44.9 & 51.8 \\
\hline No of men $(\%)$ & $902(27)$ & $998(26)$ \\
\hline \multicolumn{3}{|l|}{ Calendar year of inclusion } \\
\hline $2000-1$ & 379 & 92 \\
\hline $2002-3$ & 561 & 46 \\
\hline $2004-5$ & 948 & 62 \\
\hline $2006-7$ & 1069 & 2807 \\
\hline 2008 & 390 & 805 \\
\hline No of IgM RF seropositivet (\%) & $2411(80)$ & $2593(74)$ \\
\hline $\begin{array}{l}\text { Mean disease duration, years } \\
\text { (range) }\end{array}$ & $10.7(0-59)$ & $8.9(0-68)$ \\
\hline $\begin{array}{l}\text { Proportion with disease duration } \\
<2 \text { years }\end{array}$ & $18.7 \%$ & $31.6 \%$ \\
\hline $\begin{array}{l}\text { Mean no of tender joints of } \\
28 \text { countt (range) }\end{array}$ & $9.6(0-28)$ & $4.1(0-28)$ \\
\hline $\begin{array}{l}\text { Mean no of swollen joints of } \\
28 \text { count } \dagger \text { (range) }\end{array}$ & $7.4(0-28)$ & $2.8(0-28)$ \\
\hline Mean $\mathrm{HAO}$ score† (range) & $1.3(0-9.6)$ & $0.7(0-3.0)$ \\
\hline Mean CRP, mg/l† (range) & $27.0(0-363)$ & $15.2(0-232)$ \\
\hline Mean DAS28† (range) & $5.1(1.2-8.5)$ & $3.5(1.0-8.4)$ \\
\hline
\end{tabular}

${ }^{*}$ The number of rheumatoid arthriris (RA) patients ever treated with adalimumab was $1529(46 \%)$, etanercept $1488(44 \%)$ and infliximab $1617(48 \%)$.

tPatients with missing values were not included. The percentage of patients with missing values was as follows (ever tumour necrosis factor $\alpha$ inhibitor (TNF-I) treated, never-treated): number of IgM rheumatoid factor (RF) seropositive $(9.7 \%$, $8.4 \%)$, number of tender joints $(7.3 \%, 3.5 \%)$, number of swollen joints $(5.7 \%, 3.3 \%)$, health assessment questionnaire (HAO) score $(18.1 \%, 16.6 \%)$, C-reactive protein (CRP) $(6.4 \%, 12.3 \%)$, disease activity score in 28 joints (DAS28) $(20.4 \%, 29.4 \%)$.

\section{RESULTS}

The DANBIO arthritis cohort experienced 24,811 person-years of observation, that is, 15,592 person-years accumulated after TNF-I treatment and 9,219 person-years accumulated in nontreated (never-treated patients and before TNF-I treatment). The mean follow-up time was 2.9 years in TNF-I-treated patients and 2.1 years in non-treated patients.

Overall, we observed 280 cancers in the total DANBIO RA cohort, with 222.7 expected from the general population, yielding a standardised incidence ratio (SIR) of 1.26 (95\% CI 1.12 to 1.41). An increased SIR was observed for non-Hodgkin lymphoma 2.06 (95\% CI 1.11 to 3.83), Hodgkin lymphoma 4.81 (95\% CI 1.20 to 19.2), non-melanoma skin cancer 1.84 (95\% 1.47 to 2.31) and lung cancer 1.47 (95\% CI 1.07 to 2.03). No increased risk was observed for colon cancer 1.08 ( $95 \%$ CI 0.67 to 1.74 ).

No increase in the overall cancer risk was observed among RA patients treated with TNF-I compared to non-treated patients, whereas a significantly increased risk for all cancers was observed when comparing TNF-I-treated RA patients with the general population (table 2).

The same pattern with no increase in risk among TNF-I-treated patients relative to non-treated patients, but an increase in risk relative to the general population was seen for non-melanoma skin cancer and cancer in lymphatic and haematopoietic tissue (table 2). No increased risk of non-Hodgkin and Hodgkin lymphoma combined was observed among RA patients receiving TNF-I therapy when compared to patients not receiving therapy 0.92 (95\% CI 0.29 to 2.92 ), while an increased SIR of 2.42 (95\% CI 1.15 to 5.07) was observed when compared to the general population.

A significantly increased risk of colon cancer (HR 3.52, 95\% CI 1.11 to 11.15) was observed in TNF-I-treated RA patients compared to non-treated patients, while a non-significantly increased risk was seen compared to the general population (SIR 1.61, 95\% CI 0.93 to 2.77), based on 13 observed and 8.1 expected cases. Among non-treated patients the SIR of colon cancer was 0.53 ( $95 \%$ CI 0.20 to 1.40 ). Six cases of ovarian cancer were seen in TNF-I-treated RA patients, whereas no cases were observed in non-treated patients. The risk of ovarian cancer was non-significantly increased among those treated in comparison with the general female population (SIR $2.08,95 \%$ CI 0.94 to 4.64 ).

No significant increase in the risk for all cancer sites combined was observed in any of the non-RA arthritis groups compared to the general population.

Various adjustments for disease activity and stratified analyses in TNF-I-treated RA patients compared to non-treated patients did not reveal increased risks for overall cancer (table 3).

\section{DISCUSSION}

The strengths of our study include high coverage of biologically treated patients $(>90 \%)$ as well as a high validity of the RA, AS and PSA diagnoses in the DANBIO Registry. The registration in DANBIO was independent of registration in the cancer registry. We had complete follow-up and had the possibility to compare the cancer risks in TNF-I-treated RA patients with non-treated patients recruited from the same rheumatology departments to minimise confounding, even though confounding from factors influencing treatment decisions such as comorbidity could not be avoided. Cancer incidence in both treated and non-treated patients was also compared to that of the general population of Denmark. In clinical practice in Denmark, previous or actual cancer disease is generally a contraindication for TNF-I treatment. Therefore, to avoid differences in the prevalence of cancer among treated and nontreated patients, we excluded all patients with a previous cancer diagnosis. The cancer incidence during the first year after initiating TNF-I treatment is most likely to be influenced by selection bias, but exclusion of the first year after initiating TNF-I treatment did not change the overall risk of cancer.

We found a moderately increased overall cancer risk in RA compared to the general population. However, there was no increase in overall cancer risk among RA patients treated with TNF-I agents compared to RA non-treated patients, which is in line with other observational studies, ${ }^{3}{ }^{4} 612$ and a recent meta-analysis. ${ }^{5}$ A meta-analysis of selected randomised trials of RA patients in TNF-I treatment with adalimumab or infliximab reported a three times increased risk of cancer during short-term follow-up, ${ }^{1}$ which was not confirmed in a recent meta-analysis. ${ }^{2}$ Also in support of no effect of TNF-I on overall cancer incidence, we found no evidence of an increase in overall risk by the cumulative duration of anti-TNF therapy, and risks did not vary by sex or age at the start of treatment.

In accordance with our findings, several studies have demonstrated a two to fourfold increased risk of malignant lymphomas in RA patients compared to the general population. ${ }^{7-9} 1215$ The 
Table 2 Risk of cancer after treatment with TNF-I agents among patients with RA and patients with other types of arthritides

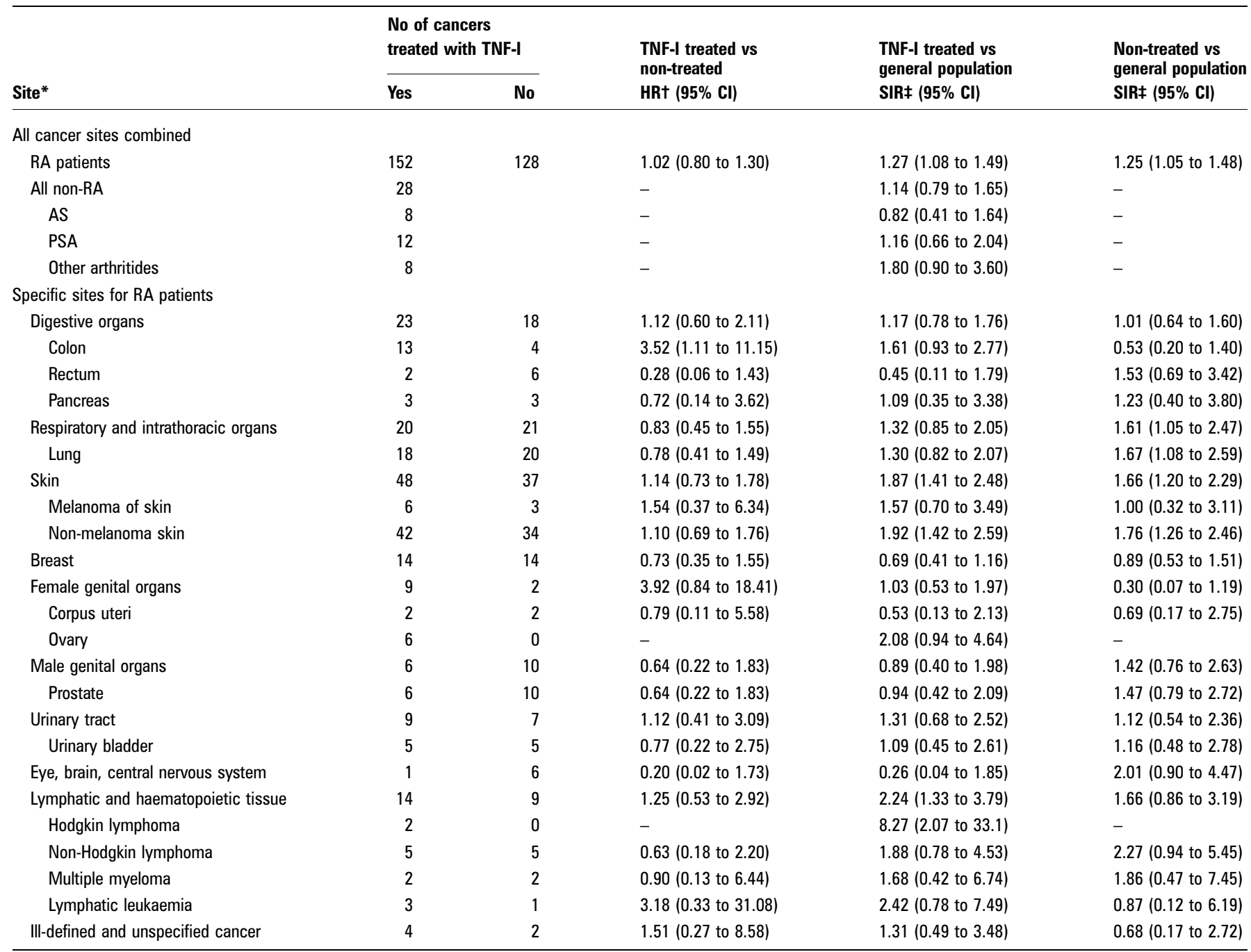

* Only specific cancer sites with more than three cases in tumour necrosis factor $\alpha$ inhibitor (TNF-I)-treated and non-treated combined are shown. Results for Hodgkin lymphoma are also presented.

tEstimated by HR ratios using Cox proportional hazard models with age as the underlying time scale and with further adjustment for sex and calendar time (2000-4, 2005-8). HR was not calculated for anlylosing spondylitis (AS), psoriatric arthritis (PSA) or other arthritides patients because of the small number of patients and short follow-up time in the non-TNF-I-treated group.

fEstimated by standardised incidence ratios (SIR), ie, the ratio between observed and expected cancer cases during follow-up. The expected number of cancer cases was calculated by multiplying the number of person-years experienced by the cohort members with sex and 5-year age and calendar-specific incidence rates for first cancers in the general population in Denmark.

RA, rheumatoid arthritis.

incidence of lymphomas was the same in our TNF-I-treated and non-treated RA patients, based on small numbers. Our results are in agreement with the conclusions of earlier studies $^{35} 781012$ except a French study. ${ }^{9}$

We found an increased incidence of non-melanoma skin cancer combining squamous and basal cell carcinomas in our RA cohort compared to the general population, which is in accordance with a previous Danish study of hospitalised RA patients ${ }^{15}$ and studies of other immunosuppressive cohorts. ${ }^{16}{ }^{17}$ However, we found that the incidence of nonmelanoma skin cancer was similar for TNF-I-treated and nontreated RA patients. A recently published British study reported that skin cancer was increased among RA patients, but found no evidence that TNF-I therapy exacerbated the risk of basal cell or squamous cell carcinomas further. ${ }^{18}$

An increased risk of colon and ovarian cancer was observed in RA patients treated with TNF-I agents compared to nontreated patients. Evidence from previous studies concerning these cancers is sparse. Wolfe and Michaud ${ }^{3}$ reported risks specifically for colon and ovarian cancer when comparing TNF-I-treated with untreated patients and the risks were not significantly elevated. Surveillance bias does not seem an obvious explanation, because increased surveillance would have been expected to result in a general increase in cancer incidence at many sites. One may hypothesise that a higher use of nonsteroidal anti-inflammatory drugs or aspirin in the diseasemodifying antirheumatic drug-treated group and a more sedentary lifestyle in the TNF-I-treated group due to higher disability, as indicated by the health assessment questionnaire or dietary factors, ${ }^{19} 20$ may affect the incidence rate of colon cancer. Larger studies are needed to determine whether the increased risks of colon and ovarian cancer were chance findings in our study.

In conclusion, we found no excess of overall cancer associated with TNF-I therapy in RA patients in routine care. However, increased risks of colon and ovary cancer were found 
Table 3 Risk of overall cancer after treatment with TNF-I agents among patients with RA by adjustment for various measures of disease activity at enrolment, gender, time since initiation, cumulative duration of treatment and age at treatment start

\begin{tabular}{|c|c|c|c|}
\hline Variable & $\begin{array}{l}\text { No of cancers } \\
\text { among treatedt }\end{array}$ & $\begin{array}{l}\text { TNF-I treated } \\
\text { versus non-treated } \\
\text { HR }(95 \% \text { CI) }\end{array}$ & p Value* \\
\hline \multicolumn{4}{|l|}{ Ever TNF-I treatment } \\
\hline Overall effect & 152 & $1.02(0.80$ to 1.30$)$ & \\
\hline Plus adjustment for HAO§ & & 0.95 (0.74 to 1.22$)$ & \\
\hline Plus adjustment for CRP§ & & $0.99(0.77$ to 1.26$)$ & \\
\hline Plus adjustment for DAS28§ & & $0.96(0.74$ to 1.24$)$ & \\
\hline Men & 48 & $0.83(0.55$ to 1.26$)$ & $p=0.24$ \\
\hline Women & 104 & $1.13(0.83$ to 1.53$)$ & \\
\hline \multicolumn{4}{|c|}{ Time since treatment initiation, years } \\
\hline$<1$ & 41 & $1.04(0.72$ to 1.50$)$ & \\
\hline $1-4$ & 97 & $1.03(0.79$ to 1.35$)$ & $p=0.86$ \\
\hline $5+$ & 14 & 0.88 (0.51 to 1.54$)$ & \\
\hline $1+$ & 111 & $1.01(0.78$ to 1.30$)$ & \\
\hline \multicolumn{4}{|c|}{ Cumulative duration of treatment, years } \\
\hline$<1$ & 43 & $1.04(0.73$ to 1.48$)$ & \\
\hline $1-2$ & 39 & $1.19(0.83$ to 1.71$)$ & $p=0.69$ \\
\hline $2-3$ & 29 & $1.09(0.72$ to 1.63$)$ & \\
\hline $4+$ & 41 & 0.86 (0.60 to 1.22$)$ & \\
\hline \multicolumn{4}{|l|}{ Age at treatment start, years } \\
\hline$<50$ & 12 & $0.83(0.38$ to 1.82$)$ & \\
\hline $50-64$ & 69 & 0.97 (0.68 to 1.37 ) & $p=0.76$ \\
\hline$\geq 65$ & 71 & $1.10(0.80$ to 1.50$)$ & \\
\hline
\end{tabular}

*p Values for homogeneity test based on Wald statistics.

tThere were 128 cancer cases observed among non-tumour necrosis factor $\alpha$ inhibitor (TNF-I)-treated patients.

fHR ratios estimated using Cox proportional hazard models with age as the underlying time scale and with further adjustment for sex and calendar time (2000-4, 2005-8).

$\S$ Adjustment for high disease activity at first visit (health assessment questionnaire (HAO) $\geq 2$; C-reactive protein (CRP) $\geq 30 \mathrm{mg} /$; disease activity score in 28 joints (DAS28) $\geq 5.1$ ). Similar results were found after adjustment for the same disease activity measures at the latest visit or at any time.

RA, rheumatoid arthritis.

and need further investigation. We did not find an increase in the overall cancer risk in TNF-I-treated AS, PSA and other arthritides patients compared to the general population.

\section{Author affiliations}

${ }^{1}$ Department of Rheumatology, Gentofte University Hospital, Hellerup, Denmark

${ }^{2}$ Danish Cancer Society Research Center, Copenhagen, Denmark

${ }^{3}$ Department of Rheumatolgy, Glostrup University Hospital, Glostrup, Denmark

${ }^{4}$ Department of Rheumatology, Frederiksberg University Hospital, Frederiksberg, Denmark

${ }^{5}$ Department of Rheumatology, Rheumatism Hospital, University of Southern Denmark, Graasten, Denmark

${ }^{6}$ Rheumatology Unit, Diagnostic Center, Region Hospital Silkeborg, Silkeborg, Denmark ${ }^{7}$ Department of Rheumatology, Holbæk University Hospital, Holbæk, Denmark

${ }^{8}$ Department of Rheumatology, Helsingør Hospital, Helsingør, Denmark

${ }^{9}$ Department of Rheumatology, Odense University Hospital, Odense, Denmark

${ }^{10}$ Department of Rheumatology, Vejle Hospital, Hospital Lillebælt, Vejle, Denmark

${ }^{11}$ Department of Infectious Diseases and Rheumatology, Rigshospitalet Universtity Hospital, Copenhagen, Denmark

${ }^{12}$ Department of Rheumatology, Køge Hospital, Køge, Denmark

${ }^{13}$ Department of Rheumatology, Vendsyssel Hospital, Hjørring, Denmark

${ }^{14}$ Department of Rheumatolgy, Aalborg University Hospital, Aalborg, Denmark

${ }^{15}$ Department of Rheumatology, Aarhus University Hospital, Aarhus, Denmark

${ }^{16} \mathrm{On}$ behalf of all departments of Rheumatology in Denmark

Contributors LD contributed to the conception and design, analysis and interpretation of data, drafting the article and revising it critically for important intellectual content and final approval of the version to be published. LM and MLH contributed to the conception and design and interpretation of data, revising the article critically for important intellectual content and final approval of the version to be published. ARA, PB, UEP, TJE, THH, DVJ, LL, HML, AGRL, HN, EO, CR, AS and UT contributed to the conception and design, revising the article critically for important intellectual content and final approval of the version to be published

Funding This article was supported with grants from The Danish Rheumatism Association and The Danish Cancer Society.

Competing interests None.

Ethics approval The project is entirely register based, and the patients have not been contacted. Therefore, no approval by the ethics committees was needed according to Danish law. Approval by the Danish Data Protection Board Agency was obtained.

Provenance and peer review Not commissioned; externally peer reviewed.

\section{REFERENCES}

1. Bongartz T, Sutton AJ, Sweeting MJ, et al. Anti-TNF therapy in rheumatoid arthritis and the risk of serious infections and malignancies: systematic review and meta-analysis of rare harmful effects in randomized controlled trials. JAMA 2006:295:2275-85

2. Askling J, Fahrbach $\mathrm{K}$, Nordstrom $\mathrm{B}$, et al. Cancer risk with tumor necrosis factor alpha (TNF) inhibitors: meta-analysis of randomized controlled trials of adalimumab, etanercept, and infliximab using patient level data. Pharmacoepidemiol Drug Saf 2011;20:119-30

3. Wolfe F, Michaud K. Biologic treatment of rheumatoid arthritis and the risk of malignancy: analyses from a large US observational study. Arthritis Rheum 2007:56:2886-95.

4. Strangfeld A, Hierse F, Rau R, et al. Risk of incident or recurrent malignancies among patients with rheumatoid arthritis exposed to biologic therapy in the German biologics register RABBIT. Arthritis Res Ther 2010;12:R5

5. Mariette X, Matucci-Cerinic M, Pavelka K, et al. Malignancies associated with tumour necrosis factor inhibitors in registries and prospective observational studies: a systematic review and meta-analysis. Ann Rheum Dis 2011:70:1895-904.

6. Geborek P, Bladström A, Turesson C, et al. Tumour necrosis factor blockers do not increase overall tumour risk in patients with rheumatoid arthritis, but may be associated with increased risk of lymphomas. Ann Rheum Dis 2005;64:699-703.

7. Askling J, Baecklund E, Granath F, et al. Anti-tumour necrosis factor therapy in rheumatoid arthritis and risk of malignant lymphomas: relative risks and time trends in the Swedish Biologics Register. Ann Rheum Dis 2009;68:648-53.

8. Wolfe F, Michaud K. Lymphoma in rheumatoid arthritis. The effect of methotrexate and anti-tumor necrosis factor therapy in 18,572 patients. Arthritis Rheum 2004:50:1740-51.

9. Mariette $\mathbf{X}$, Tubach $\mathrm{F}$, Bagheri $\mathrm{H}$, et al. Lymphoma in patients treated with anti-TNF: results of the 3-year prospective French RATIO registry. Ann Rheum Dis 2010;69:400-8.

10. Baecklund $\mathbf{E}$, lliadou A, Askling J, et al. Association of chronic inflammation, not its treatment, with increased lymphoma risk in rheumatoid arthritis. Arthritis Rheum 2006;54:692-701.

11. Askling J, Fored CM, Brandt $\mathrm{L}$, et al. Risks of solid cancers in patients with rheumatoid arthritis and after treatment with tumour necrosis factor antagonists. Ann Rheum Dis 2005:64:1421-6.

12. Setoguchi S, Solomon DH, Weinblatt ME, et al. Tumor necrosis factor $\alpha$ antagonist use and cancer in patients with rheumatoid arthritis. Arthritis Rheum 2006;54:2757-64

13. Hetland ML. DANBIO - powerful research database and electronic patient record Rheumatology 2011:50:69-77.

14. Linde L, Sørensen J, Østergaard M, et al. What factors influence the health status of patients with rheumatoid arthritis measured by the SF-12v2 Health Survey and the Health Assessment Questionnaire? J Rheumatol 2009;36:2183-9.

15. Mellemkjær L, Linet MS, Gridley G, et al. Rheumatoid arthritis and cancer risk. Eur J Cancer 1996;32A:1753-7.

16. Dreyer L, Faurschou M, Mogensen M, et al. High incidence of potentially virus-induced malignancies in systemic lupus erythematosus: a long-term followup study in a Danish cohort. Arthritis Rheum 2011;63:3032-7.

17. Wisgerhof HC, van der Geest LG, de Fijter JW, et al. Incidence of cancer in kidney-transplant recipients: a long-term cohort study in a single center. Cancer Epidemiol 2011:35:105-11.

18. Mercer LK, Green AC, Galloway JB, et al. The influence of anti-TNF therapy upon incidence of keratinocyte skin cancer in patients with rheumatoid arthritis: longitudinal results from the British Society for Rheumatology Biologics Register. Ann Rheum Dis 2012;71:869-74.

19. Magalhães B, Peleteiro B, Lunet N. Dietary patterns and colorectal cancer: systematic review and meta-analysis. Eur J Cancer Prev 2012;21:15-23.

20. Wolin KY, Yan Y, Colditz GA. Physical activity and risk of colon adenoma: a meta-analysis. Br J Cancer 2011;104:882-5. 